\title{
Analysis of interaction among land use, transportation network and air pollution using stochastic nonlinear programming
}

\author{
N. Shahraki • M. Turkay
}

Received: 30 November 2013/Revised: 24 February 2014/ Accepted: 17 March 2014/Published online: 10 April 2014

(C) Islamic Azad University (IAU) 2014

\begin{abstract}
This paper presents two novel models for land use and transportation to address the development of different functional zones in urban areas by considering the design of an efficient transportation network and reducing air pollution. Objective functions of the first model are maximizing utility function and maximizing reliability index. The utility is formulated as a function of travel cost and zonal attractiveness. Reliability index is defined as the probability that flow in each link of the network is less than the design capacity. Maximizing this probability is equivalent to minimizing congestion in the network. In addition, maximizing utility and minimizing carbon monoxide emission in the network are considered as objective functions in the second model. The formulated models are nonlinear and stochastic. We implement the $\varepsilon$-constraint method for solving these bi-objective optimization problems. We analyze the models and solution characteristics of some examples. In addition, we evaluate the relation between computing time and complexity of the model. In this study, for the first time in the open literature, stochastic bi-objective optimization models are formulated to analyze interaction among land use, transportation network and air pollution. We also extract and summarize some useful insights on the relationship among land use, transportation network and environmental impact associated with them.
\end{abstract}

Electronic supplementary material The online version of this article (doi:10.1007/s13762-014-0566-3) contains supplementary material, which is available to authorized users.

N. Shahraki $\cdot$ M. Turkay $(\bowtie)$

Department of Industrial Engineering, Koc University,

Rumelifeneri Yolu, Sariyer, Istanbul 34450, Turkey

e-mail: mturkay@ku.edu.tr
Keywords Urban design - Carbon monoxide emission . Land use · Transportation - Optimization

\section{Introduction}

Integrated analysis of land use and transportation is attracting attention of academics and urban designers due to growing interest from public agencies that need to improve their capacity to respond to complex policy questions arising in the context of transportation, land use and quantifying the environmental impact associated with them. The relationship between transportation and land use is highly complex; spatial interactions between land use and transportation are keys to explaining movements of passengers and freight. Land use is associated with demographic and economic attributes, while the transportation system moves passengers and freight by certain modes on the transportation network (Rodrigue et al. 2006). In addition, interactions among economic, social and environmental impacts of the decisions related to land use and transportation necessitates the development of methodical approaches that would be instrumental in the decision-making process.

An important consideration in the land use and transportation network design is the environmental impact assessment. On the average, road transportation contributes $95 \%$ of the carbon monoxide (CO) and $35 \%$ of the nitrogen oxides in urban environments (Environmental Protection Agency 2010; FHWA 2006). It is reported that most of the air pollution in Tehran metropolitan area, the most polluted city among urbanized cities in developing countries, is contributed by transport (Abbaspour and Soltaninejad 2004). These air pollutants can have 
potentially serious consequences for both the ecosystem and the human health ( $\mathrm{Ng}$ and Lo 2013).

The integration of different functional zones in urban areas that include housing, commerce, retail, industrial, and service sector needs is an important consideration in land use. An efficient integration of these functionalities requires links among them such as transportation infrastructure elements (i.e., roads, stations, mode change hubs, etc.) and proper land allocation; therefore, an effective solution to this problem is very important to reduce air pollutants in the cities. Liao et al. (2013) reported that relationships among land use, urbanization and emissions are highly related to transportation characteristics. It was also shown that unplanned urbanization causes severe environmental problems in cities (Alam et al. 2006).

Newman and Kenworthy (1989) argued that, in modern societies, a city with extremely low land use intensity and degree of concentration has very low traffic restraints and intensive automobile orientation; and further, an extremely poor transit system, very high gasoline use and consequently too much air pollution. In constraint, a city that is organized with very high density and very strong degree of concentration must relate to strong traffic restraints and intensive non-auto modes-public transit, cycling or walking and less air pollution.

Land use and transportation systems are closely intertwined, and models used to support transportation planning need to be integrated with land use models as has been discussed numerous times in the literature (see e.g., Paulley and Webster 1991; Southworth 1995; Garret and Wachs 1996; Miller et al. 1999; Environmental Protection Agency 2000; Wegener 2004; Wegener and Furst 2004; Dowling et al. 2005; Waddell et al. 2007; Newman and Kenworthy 1989).

Figure 1 (adopted from Wegener 1995) shows the circular interrelationship between transportation and land use. In this cycle, land use and transportation are interdependent through accessibility and activities. This figure provides a comprehensive understanding of the behavior of actors in the urban system while also taking into account the natural processes that take place within this system (Kanaroglou and Scott 2002).

A large number of models have been developed to address the integration of the network design and land use problems such as Lowry (1964), DELTA/START (Simmonds and Still 1998), IMREL (Anderstig and Mattsson 1998), IRPUD (Wegener 1998b), ITLUP (Putman 1983),
Fig. 1 The land use transport feedback cycle (adopted from Wegener 1995)

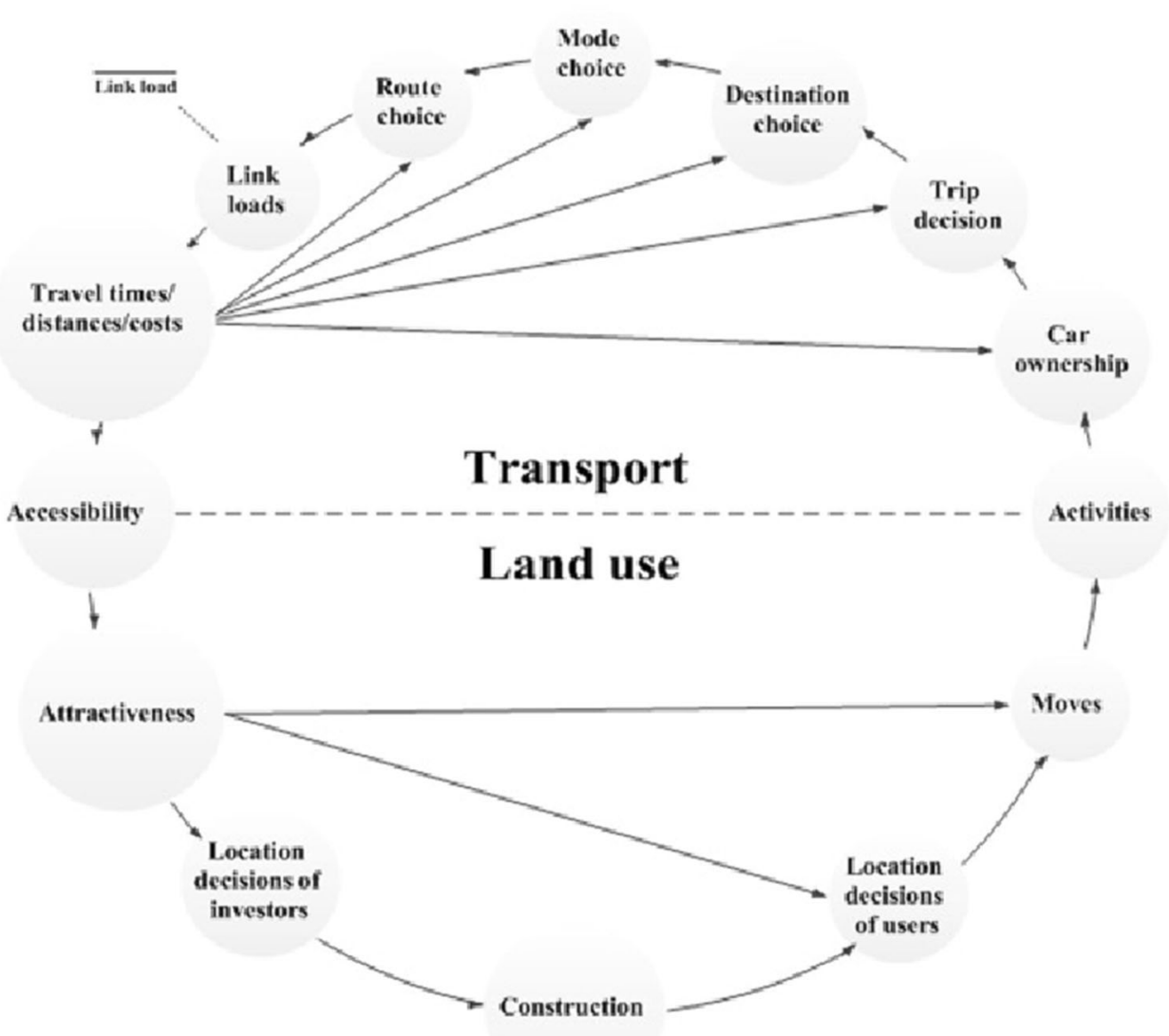


LILT (Mackett 1983), MEPLAN (Echenique et al. 1969), METROSIM (Anas 1987), MUSSA (Martinez 1992, 1996), TRANUS (De la Barra et al. 1984) and ITLUP (Putman 1983; Timmermans 2003). In spite of the fact that there are numerous land use and transportation models in literature, but little attention has been paid to simultaneous optimization of land use and transportation network design (Yim et al. 2011).

Previously, Lin and Feng (2003), Hui and Kefei (2009), Ho and Wong (2007) and Yim et al. (2011) have presented bi-level models for formulating a land use and network design optimization problem. Lin and Feng (2003) developed a subprogram as an upper level to allocate different land uses, links and facilities to different areas of a city, and a lower-level subprogram to design the network. In Hui and Kefei (2009), the location of different communities of a city is considered as an upper-level problem, while the network design is handled at the lower level. Ho and Wong (2007) formulated a bi-level model. In the upper level of the model, a utility function is maximized for the allocation problem and transportation network is designed in the lower level of the problem. Moreover, every parameter is considered as deterministic in these studies. A stochastic land use and transportation optimization model as a bilevel programming problem was presented by Yim et al. (2011). Optimal residential allocation, employment allocation and capacity enhancements are determined by maximizing the reliability index of the network in the upper level. The lower-level subprogram is formulated to determine optimal route choices behavior by minimizing the total travel cost. A genetic algorithm is used as the solution method. Zonal attraction and travel time are also two important factors for residential allocation and employment allocation that are not considered in previous models.

Chang and Mackett (2006) presented a bi-level model to show the relationship between transport and residential location. In this model, residents choose their location based on locational attractiveness. Bravo et al. (2010) developed a model where households select their resident location base on locational attractiveness and travel cost. Ma and Lo (2012) formulated a dynamic residents' location and travel choices dynamic model, with considering the housing supply problem. They developed a utility function base on locational attractiveness and travel cost as objective function of residents for selecting their location. In these studies, the travel demand has been considered as static. Meanwhile, the travel demand is highly depends on the pattern of activities in urban area. The timing and locations of these activities indicate that travel demand is not uniform throughout the day (Sheffi 1985). Besides, Kitamura and Susilo (2005) found that that travel demand is not stable over time by conducting a statistical analysis.
A large number of static network design studies focus on the economic dimension of sustainability (e.g., Ban et al. 2006; Kim et al. 2008; Lo and Szeto 2009). Zhou et al. (2008), Yin and Lu (1999) and Huang et al. (2010) solely considered environmental sustainability and used total traffic emissions as an indicator. Some studies have developed a bi-objective formulation to incorporate environmental and economic factors (e.g., Sharma and Mathew 2011; Miandoabchi et al. 2012a, b; Yin and Lawphongpanich 2006; Ferguson et al. 2010; Li et al. 2012; Yang et al. 2010; Zhong et al. 2012). In these studies, land use planning is not incorporated.

Szeto et al. (2010) developed a dynamic land use and transportation optimization model to show the interaction between land use and transportation. Szeto and Jiang (2013) extended this model to a sustainable model. In this model, environmental, economic and social dimensions of a sustainable system are considered as a multi-objective formulation. But in this model, demand in each period is constant.

In this paper, we present two bi-objective stochastic optimization models to analyze the interaction among land use, transportation network and air pollution. We consider demand as a random variable that affects reliability index, utility function of different income groups and amount of $\mathrm{CO}$ emission. In the first model, reliability index and utility function are maximized and the value for $\mathrm{CO}$ emission is calculated. In the second model, the utility function is maximized and $\mathrm{CO}$ emission is minimized and the value for reliability index is calculated. By developing two separate models, we can analyze the relation among reliability index, utility value and CO emission. In this manner, we can develop better insights about their relations. In the first model, we calculate $\mathrm{CO}$ emission value for a city structure with optimal value for utility and congestion. And we analyze the relation between $\mathrm{CO}$ emission amount and two objectives. In the second model, we analyze how network structure changes by considering minimizing $\mathrm{CO}$ emission as an objective function.

We consider minimization of the probability of congestion by maximizing the reliability in each link, which received little attention in the published literature. Congestion is minimized by changing the distribution of flow in the network and expanding the capacity of the links which are considered as decision variables. And by maximizing the utility function, we minimize travel time and maximize locational attractiveness of residents which are presented as cost in the utility function. Utility value, congestion and $\mathrm{CO}$ emission are given in the models, respectively, as economic, social and environmental dimensions of a sustainable system.

Developing two models to allocate residential development and designing a transportation network based on four 
factors; minimizing congestion, maximizing locational attractiveness of residents, minimizing travel cost and minimizing $\mathrm{CO}$ emission, by considering stochastic travel demand are the main contribution of this paper. In addition, we propose an effective solution algorithm and illustrate the efficiency of our approach on a large number of instances. In this study, for the first time in literature to our knowledge, an integrated stochastic land use and transportation model is formulated by considering two objective functions. This work is carried out at Koc University, industrial engineering department in 2013 from January to November.

The decision maker in our model is the network planner. Network planner simulates the network and residential behaviors by developing optimization models. The decision maker can find answers for different questions such as, which income group prefers which zones, which zones should be expanded, which links are more crowded, which links are more polluted, which links should be augmented and how much travel cost is in each link, by solving the optimization models.

\section{Materials and methods}

A brief description of the transportation system under investigation is presented in this section. We consider a transportation network $G(N, A)$, where $N$ is the set of nodes and $A$ is the set of links. Some nodes are considered to be origin nodes and some to be destination nodes; the remainders are called intermediate nodes. Origin and destination nodes can represent the same geographical location. $P$ is the set of origin nodes, $Q$ is the set of destination nodes and $R$ is the set of routes between pair $p-q$.

The decisions by residents include both location (residential location and workplace) and corresponding travel choices. Normally, residents do not control the choice of workplace; this depends on the availability of specific employment types. In addition, the decision maker in this process is an individual. In contrast, residents have more authority in choosing their own housing locations, and residence choice is made jointly by a household that may have multiple members (Ma and Lo 2012). In this study, the workplace choices by residents are not considered.

The choice of residential location is the result of a tradeoff between attraction and travel time. A more plausible assumption would be that the residents try to accomplish two goals: travel to the destination with the highest attraction measure while spending the minimum time in transit (Sheffi 1985). Ibeas et al. (2013) found that homework journey times are a statistically significant factor in household location choice, by implementing their model in a real case. In this paper, we consider home-work journey flows in our model.

We divide the residential development with workplace at $q$, into $k$ different groups based on their income. They try to choose their residential locations in one of the origin nodes that maximize their utility. This utility function is composed of zonal attractiveness and travel time. In addition, we consider that the network planner also has resources to improve the network by augmenting the capacity of the existing links in the network. Network planner tries to maximize the reliability of the network by expanding the capacity of the links. We assume the decision maker in both problems is the network planner, and we develop a single model. The decision maker tries to simulate residential behavior to make decision for expanding capacity of zones and links of the network. In this problem, we formulate an environmental objective to minimize transport $\mathrm{CO}$ emission. We consider $\mathrm{CO}$ emission due to three reasons: (1) Almost all $\mathrm{CO}$ emissions in the air are produced by vehicles, (2) $\mathrm{CO}$ is the most important pollutant among the different types of vehicular emissions, which include nitrogen oxide, $\mathrm{CO}$, nitrogen dioxide, sulfur dioxide, ozone, and particulates, and (3) The emission rates of other pollutants are similar to that of CO (Li et al. 2012).

\section{Mathematical model for land use and transportation}

In this paper, we assume that the demand from origin to destination nodes, $d_{p q}$, is a random variable that follows a certain probability distribution with mean and variance as follows:

$E\left(d_{p q}\right)=\bar{d}_{p q}$
$\operatorname{var}\left(d_{p q}\right)=\sigma_{p q}^{2}$

Considering the demand as a random variable is more realistic than considering it as a constant value.

Also, we assume that the demands from origin to destination nodes are mutually independent. The flow in each link is defined as in Eq. (3).

$x_{a}=\sum_{p \in P} \sum_{q \in Q} \sum_{r \in R_{p q}} d_{p q} \gamma_{p q r} \delta_{p q r a}$

In Eq. (3), $\gamma_{p q r}$ is the vector of route choice proportions and $\delta_{p q r a}$ is the link-path incidence matrix that is equal to 1 if the route $r$ passes through link $a$ otherwise it is equal to 0. $x_{a}$ is a random variable that is function of transportation demand as shown in Eq. (3). The demand $\left(d_{p q}\right)$ is function of residential development amount, so flow in each link $\left(x_{a}\right)$ is indirectly function of amount of developments. The average of flow in each link formulates as follows, 
$\bar{x}_{a}=\sum_{p \in P} \sum_{q \in Q} \sum_{r \in R_{p q}} \bar{d}_{p q} \gamma_{p q r} \delta_{p q r a}$

Considering $d_{p q}$ as a random variable makes the problem nonlinear since $\gamma_{p q r}$ is also decision variable in our model. In Previous studies except in Yim et al. (2011), a variable introduces instead of $d_{p q} \gamma_{p q r}$, since $d_{p q}$ is not considered as a random variable. So, those models do not suffer from this nonlinear term.

We consider reliability index as the first objective in our problem. The reliability index as shown in Eq. (5) is the probability that flow in each link be less the practical capacity $\left(\mathrm{Ca}_{a}\right)$ of the link plus the amount of capacity expansion $\left(y_{a}\right)$ that is a decision variable in our problem.

$\pi=P\left\{x_{a} \leq \mathrm{Ca}_{a}+y_{a}\right\}$

This probability can be obtained from the approximated multivariate normal distribution presented by Genz (1992). The algorithm is composed of five steps, in step two, the lower triangle of Cholesky factorization matrix must be calculated. The reader can refer to Genz (1992) for the details of this five-step algorithm.

The elements of the Cholesky matrix can be derived from the covariance of flow between links, and the covariance is function of mean demand and route choice proportion that are decision variables of the problem, as shown in Eq. (6).

$$
\begin{aligned}
\operatorname{cov}\left(x_{a}, x_{\hat{a}}\right) & =E\left(\left(x_{a}-\bar{x}_{a}\right)\left(x_{\hat{a}}-\bar{x}_{\hat{a}}\right)\right) \\
& =\sum_{p \in P} \sum_{q \in Q} \sum_{r \in R_{p q}} \sum_{r \in R_{p} \hat{q}} E\left(\left(d_{p q}-\bar{d}_{p q}\right)^{2}\right) \gamma_{p q r} \gamma_{\hat{p} \hat{r} \hat{r}} \delta_{p q r a} \delta_{\hat{p} \hat{q} \hat{r} \hat{a}} \\
& =\sum_{p \in P} \sum_{q \in Q} \sum_{r \in R_{p q}} \sum_{\hat{r} \in R_{p \hat{p}}} \sigma_{p q}^{2} \gamma_{p q r} \gamma_{\hat{p} \hat{r} \hat{r}} \delta_{p q r a} \delta_{\hat{p} \hat{q} \hat{r} \hat{a}}
\end{aligned}
$$

We present a closed form expression for calculating lower triangle of the Cholesky factorization matrix as shown in Fig. 2 and implement this expression in our model as a set of constraints. In Fig. 2, $c_{i j}$ are the elements of the Cholesky matrix and $a_{i j}$ are the elements of the matrix of the covariance of flow between the links.

The problem assumes that each residential location is associated with an attraction measure. Travelers are assumed to choose destinations that are attractive, on the one hand, and close by low travel cost value, on the other. In this model destinations are chosen so that the utility function that is the difference between travel cost value and attractiveness value is maximized. We consider the utility function as shown in Eq. (7) (Ma and Lo 2012) as the second objective in our model. In this function, $I^{k}$ is the income of group $k$, and $g\left(\varphi^{q k}\right)$ is the expenses set aside to achieve the resident's desired level of utility $\varphi_{q k}$ in aspects other than transport and location choices. In addition, $\mu^{p q k}$ is travel cost between zone $p$ and $q$ for income group $k$ and

$$
\begin{aligned}
& \text { for } j=1, \ldots, N \text {; } \\
& \text { if } j=1, c_{j j}=\sqrt{a_{j j}} \\
& \text { otherwise, } c_{j j}=\sqrt{a_{j j}-\sum_{n=1}^{j-1} c_{j n} c_{j n}} \\
& \text { for } i=1, \ldots, j-1 ; \& j \geq 2 ; \\
& c_{i j}=0 \\
& \text { end } \\
& \text { for } i=j+1, \ldots, N ; \\
& \text { if } j=1, c_{j i}=\frac{1}{c_{j j}} a_{j i} \\
& \text { otherwise, } c_{j i}=\frac{1}{c_{j j}}\left(a_{j i}-\sum_{n=1}^{j-1} c_{j n} c_{i n}\right)
\end{aligned}
$$

end

end

Fig. 2 Algorithm for calculating the lower triangle of Cholesky factorization matrix

$l^{p k}$ is the attractiveness of zone $p$ as valuated by income group $k$.

$\varphi=I^{k}-g\left(\varphi^{q k}\right)-\mu^{p q k}+l^{p k}$

where,

$l^{p k}=l_{0}^{p k}-\theta_{1}^{p k}\left(\frac{h_{p}+H_{p}}{K_{p}}\right)^{\rho_{2}^{p k}}$

$\mu^{p q k}=\delta_{p q r a}\left(\operatorname{vot}^{k} t_{a}+\rho_{a}\right)$

The utility function defined in Eq. (7) represents the value that a household of income group $k$ at workplace $q$ is willing to pay for residential location $p$. The fourth term in this function $l^{p k}$ shows the impact of population allocation on zonal attractiveness. As shown in Eq. (8), this term includes two types of zonal attractiveness. The $l_{0}^{p k}$ is called intrinsic attractiveness which is an exogenous constant, and second term in Eq. (8) is a measure of the effect of land use intensity or congestion on zonal attractiveness. $H_{p}$ and $h_{p}$ are total existing population in zone $p$, and total amount of residential development in zone $p$, respectively. $K_{p}$ shows the holding capacity within zone $p$. In addition, $\theta_{1}^{p k}$ and $\theta_{2}^{p k}$ are constant coefficients.

Ma and Lo (2012) stated that to express the impact of zonal attractiveness measures better, other aspects of a zone such as hedonic housing attributes, like lot size, building age, floor level and living amenities can be considered. Also, environmental condition of a zone can be an important aspect to attract residents.

In Eq. (9), $t_{a}$ is the travel time in each link that is multiplied by the value of time $\left(\operatorname{vot}^{k}\right)$ of residents in income group $k$, and this expression is added to toll charges $\left(\rho_{a}\right)$ to show the travel cost in link $a$. We use the Bureau of 
Public Roads (BPR) link impedance function in Eq. (10) in order to formulate the total travel time function.

$t_{a}=t_{0}^{a}\left(1+\beta\left(\frac{x_{a}}{\mathrm{Ca}_{a}}\right)^{\alpha}\right)$

In Eq. (10), $t_{a}^{0}$ is the free-flow travel time of link $a$, and $\beta$ and $\alpha$ are the model parameters. The values for $\beta$ and $\alpha$ are typically considered equal to 0.15 and 4.0, respectively. In this problem, the practical capacity of a link is summation of initial capacity of the link plus amount of expansion which is decision variable in our problem. So, the long-run perceived travel time can be presented as follows:

$E\left(t_{a}\right)=t_{0}^{a}\left(1+\frac{0.15}{\left(\mathrm{Ca}_{a}+y_{a}\right)^{4}} E\left(x_{a}^{4}\right)\right)$

We assume that $x_{a}$ follows normal distribution with mean $\bar{x}_{a}$ and standard deviation $\sigma_{a}$. The fourth uncentered moment of the distribution can be expressed from the central limit theorem as follows.

$E\left(x_{a}^{4}\right)=\bar{x}_{a}^{4}+6 \sigma_{a}^{2} \bar{x}_{a}^{2}+3 \sigma_{a}^{4}$

Therefore, we can rewrite the long-run perceived travel time as in Eq. (13).

$\bar{C}_{a}\left(\bar{x}_{a} ; \bar{d}, \gamma, \delta\right)=t_{a}^{0}\left(1+\frac{0.15}{\left(\mathrm{Ca}_{\mathrm{a}}+\mathrm{y}_{\mathrm{a}}\right)^{4}}\left(\bar{x}_{a}^{4}+6 \sigma_{a}^{2} \bar{x}_{a}^{2}+3 \sigma_{a}^{4}\right)\right)$

The variance of the link flow can be expressed as a function of the mean origin-destination demands, route choice proportions and link-path incident matrix as shown in Eq. (14).

$$
\begin{aligned}
\sigma_{a}^{2}=\operatorname{var}\left(x_{a}\right) & =E\left(\left(x_{a}-\bar{x}_{a}\right)^{2}\right) \\
& =E\left(\left(\sum_{p \in P} \sum_{q \in Q} \sum_{r \in R_{p q}}\left(d_{p q}-\bar{d}_{p q}\right) \gamma_{p q r} \delta_{p q r a}\right)^{2}\right) \\
& =\sum_{p \in P} \sum_{q \in Q} \sum_{r \in R_{p q}} \sum_{\hat{r} \in R_{p q}} \sigma_{p q}^{2} \gamma_{p q r} \gamma_{p q \hat{r}} \delta_{p q r a} \delta_{p q \hat{r} a}
\end{aligned}
$$

$\mathrm{CO}$ emission in each link is calculated by Eq. (15). The amount of $\mathrm{CO}$ emission is function of the length of each link $\left(l_{a}\right)$, the travel time in each link $\left(t_{a}\right)$ and the travel speed in each link $\left(l_{a} / t_{a}\right)$. This formula has been discussed in detail in Yin and Lawphongpanich (2006), Szeto et al. (2010) and $\mathrm{Ng}$ and Lo (2013).

$e_{a}=0.2038 t_{a} \exp ^{0.7962\left(l_{a} / t_{a}\right)}$
Model I: reliability probability and utility

The objective functions of model I are presented in Eqs. (16) and (17) that are reliability probability and utility, respectively. The model contains 16 different set of constraints (Eqs. 18-33). Equation (18) expresses the amount of residential developments of each income group that is allocated to origin nodes and Eq. (19) shows the total amount of residential development. In Eq. (20), the budget limit for allocating and enhancing the capacity of each link is given. Equation (21) shows there is limitation in income of each group. So, the average price of a house in zone $p$ plus average travel cost of group $k$ to travel to zone $p$ should be less than the income of group $k$. Equation (22) shows the minimum and maximum capacity expansion limits on link $a$. Equation (23) expresses that the summation of the vector of route choice proportions between origin-destination pair $p-q$ should be equal to 1 . To illustrate the amount of production/attraction in origin and destination zones, Eqs. (24) and (25) are presented. The amount of household development of income group $k$ at the workplace $q$ is represented with $z_{q}^{k}$ and $E_{q}$ is total existing population in zone $q$. Equation (26) expresses the capacity limit in each zone. Also, Eq. (27) shows the average flow in each link. Besides, amount of CO emission in the network is formulated in Eq. (28). The decision variables are $h_{p}^{k}, \bar{x}_{a}$, $\gamma_{p q}, y_{a}$ and $\bar{d}_{p q}$ that are, respectively, the amount of household of each income group that is allocated to origin zones, the average flow in each link, the vector of route choice proportions, the capacity expansion of each link and the average demand between origin and destination nodes.

$\max \pi=P\left(x_{a} \leq \mathrm{Ca}_{a}+y_{a}\right)$

$\max \varphi=I^{k}-g\left(U^{q k}\right)-\mu^{p q k}+I^{p k}$

subject to

$\sum_{p \in P} h_{q}^{k}=z_{q}^{k} \quad \forall q \in Q, \forall k \in K$

$\sum_{k \in K} h_{p}^{k}=h_{p} \quad \forall p \in P$

$B_{o}(O)+B_{y}(y) \leq B_{g}$

$\bar{\rho}_{p}+\sum_{k \in k} \sum_{q \in Q} \mu^{p q k} \leq I^{k} \quad \forall p \in P, \forall k \in K$

$0 \leq y_{a}^{\min } \leq y_{a} \leq y_{a}^{\max } \quad \forall a \in A$

$\sum_{r \in R_{p q}} \gamma_{p q r}=1$

$\sum_{p \in P} \bar{d}_{p q}=E_{q}+\sum_{k \in K} z_{q}^{k} \quad \forall q \in Q$ 
$\sum_{q \in Q} \bar{d}_{p q}=H_{p}+\sum_{k \in K} h_{p}^{k} \quad \forall p \in P$

$h_{p}+H_{p} \leq K_{p} \quad \forall p \in P$

$\sum_{p \in P} \sum_{q \in Q} \sum_{r \in R_{p q}} \bar{d}_{p q} \gamma_{p q r} \delta_{p q r a}=\bar{x}_{a} \quad \forall a \in A, \forall k \in K$

$e=\sum_{a \in A} 0.2038 t_{a} \exp ^{0.7962\left(l_{a} / t_{a}\right)}$

$\bar{x}_{a} \geq 0 \quad \forall a \in A$

$y_{a} \geq 0 \quad \forall a \in A$

$\gamma_{p q r} \geq 0 \quad \forall p \in P, \forall q \in Q, \forall r \in R$

$\bar{d}_{p q} \geq 0 \quad \forall p \in P, \forall q \in Q$

$h_{p}^{k} \geq 0 \quad \forall p \in P$

The presented mathematical model is a bi-objective nonlinear problem (NLP). The bi-linear term $\bar{d}_{p q} \gamma_{p q r}$ in Eqs. (16), (17) and (27) introduces non-convexities. In Eq. (17), Cholesky matrix elements should be used which include bi-linear terms are and also the travel cost in Eq. (16) has this bi-linear term.

\section{Model II: CO emission and utility}

In previous section, we developed a model to design land use and transportation network based on maximizing utility and reliability index, and $\mathrm{CO}$ emission is calculated as a constraint. The goal for developing previous model is to analyze the relationship between different land use and transport system structure and amount of $\mathrm{CO}$ emission. In this part, we introduce another model which is minimizing $\mathrm{CO}$ emission and maximizing utility value. Examining how the decisions by travelers and network structure change based on minimizing emission is the aim of this model. In addition, we can find if there are significant differences between results of two models.

The difference between this model and previous model [Eqs. (16)-(33)] is in the objective functions. We consider minimizing total $\mathrm{CO}$ emission in the network as the first objective Eq. (34) and maximizing utility as the second objective function Eq. (17). The reliability index is given as a constraint in our model $\left(\pi=P\left(x_{a} \leq \mathrm{Ca}_{a}+y_{a}\right)\right)$. The rest of the constraints are same as in the previous model [Eq. (16)-(33)].

$\min e=\sum_{a \in A} 0.2038 t_{a} \exp ^{0.7962\left(l_{a} / t_{a}\right)}$

Solution algorithm

There are a number of methods to solve multi-objective problems. One of these methods is $\varepsilon$-constraint method. This method is applicable for both linear and nonlinear problems. In this approach, the multi-objective problem is reformulated by keeping one of the objectives and restricting the rest of the objectives within user-specified values. The modified problem in its generic form is as follows:

$\min f_{\mu}(x)$

subject to

$$
\begin{aligned}
& f_{m}(x) \leq \epsilon_{m} \quad m=1,2, \ldots, M \text { and } m \neq \mu \\
& g_{j}(x) \leq 0 \quad j=1,2, \ldots, J \\
& h_{k}(x)=0 \quad k=1,2, \ldots, K \\
& x_{i}^{(L)} \leq x_{i} \leq x_{i}^{(U)} \quad j=1,2, \ldots, I
\end{aligned}
$$

where the parameters $\varepsilon_{m}$ represents an upper bound of the value of the $m$ th objective function, $f_{m}$ (Deb 2001).

The optimization models presented in the previous sections [Eqs. (16)-(34)] are bi-objective optimization problems: The first objective of model I is maximizing the reliability index, and the first objective of model II is minimizing $\mathrm{CO}$ emission. The second objective of both problems is maximizing the utility. In our implementation of the solution algorithm, we keep the first objective (reliability index in model I and CO emission in model II) as the objective function of the problem and we consider the second objective as a constraint that should be greater than a $\varepsilon$, where $\varepsilon$ is a lower bound of the utility value. The value of $\varepsilon$ should change from the worst to the best value of the utility to generate the family of solutions representing the Pareto set. We define a variable named "counter" to generate different Pareto points, and we substitute the constraint $\varphi \geq \varepsilon$ with the following constraint,

$\varphi \geq \varphi_{\text {upper }}-\tau($ counter $)$

with

$\tau($ counter $)=\operatorname{ord}($ counter $) \times \omega$

$w=\left(\varphi_{\text {upper }}-\varphi_{\text {lower }}\right) / \operatorname{card}($ counter $)$

where $\varphi_{\text {lower }}$ and $\varphi_{\text {upper }}$ are lower and upper bounds for the utility function, respectively.

Our modified problems are as follows:

$\max \pi$

subject to

$\varphi \geq \varphi_{\text {upper }}-\tau$ (counter)

$e=\sum_{a \in A} 0.2038 t_{a} \exp ^{0.7962\left(l_{a} / t_{a}\right)}$

Eqs. (18) $-(33)$

$\min e$

subject to

$\varphi \geq \varphi_{\text {upper }}-\tau$ (counter)

$\pi=P\left(x_{a} \leq \mathrm{Ca}_{a}+y_{a}\right)$

Eqs. (18) $-(33)$ 
We define two problems to calculate the upper and lower values for the utility. By solving Eqs. (39)-(40) without considering $\varphi \geq \varphi_{\text {upper }}-\tau$ (counter), we obtain the best value for the first objectives. By inserting the results of this problem in utility function, we obtain lower bound for utility value. In the same manner, by optimizing the problem in Eq. (41), we obtain the upper value for the utility function. We obtain the worst value for the first objective functions by putting the results of this problem in the first functions.

$\max \varphi$

subject to

Eqs. (18) $-(33)$

We generate Pareto optimal solutions for model I and model II by optimizing Eqs. (39) and (40), respectively, for "counter" between 1 and $N$.

\section{Results and discussion}

In this section, first an illustrative example is presented. Then, a sensitivity analysis of key parameters is provided for this illustrative example. Last, we provide results for a large set of problems.

\section{Illustrative example}

We use the data presented in Yim et al. (2011), Ma and Lo (2012) and $\mathrm{Ng}$ and Lo (2013) for the illustration of our models and the results. Figure 3 shows the layout of the example network consisting of six nodes, seven links, two origins and two destinations. The characteristics of links, zones and income groups are listed in Table 1. We assume that demand follows Poisson's distribution with equal mean and variance. The capacity of network links is allowed to expand up to $20 \%$ of the existing link capacity. Hence, we have $0 \leq y_{a} \leq 0.2 C_{a}$. The budget for network expansion and residential developments is given by,

$B_{y}=\sum_{a \in A} 0.3 y_{a}^{2}, B_{h}=\sum_{p \in P} h_{p}^{2}$

The maximum budget for the land use development and network enhancement is assumed as $\$ 450$ million. In addition, we consider that there is population growth of 20.000 , which requires the land development equal to 20 house units in the city. The values of parameters $\theta_{1}^{p k}$ and $\theta_{2}^{p k}$ are considered 5 and 2 , respectively.

The results of solving the problem by implementing model I and model II are reported in "Results for model I" and "Result for model II" section, respectively, and the efficient frontiers of optimal solutions are plotted in Fig. 4.

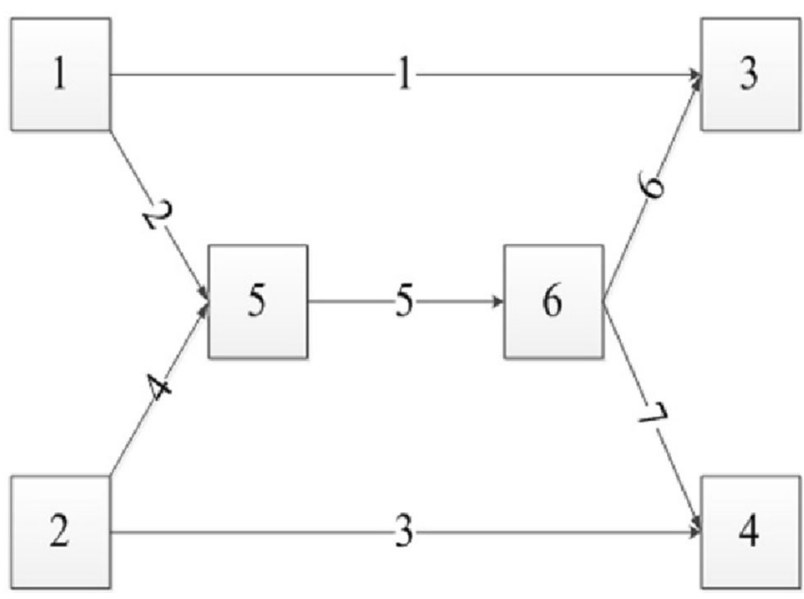

Fig. 3 The schematic drawing of the numerical example

Table 1 The characteristics of the illustrative example

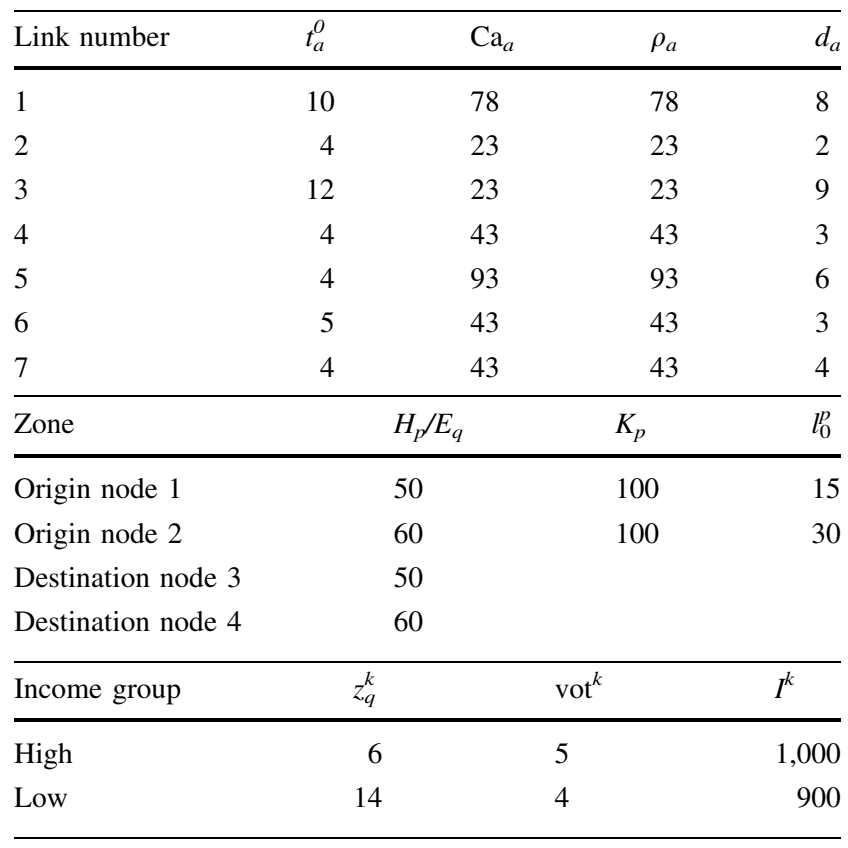

All runs were performed on a PC Intel(R), Xeon(R), central processing unit (CPU) $3.33 \mathrm{GHz}$ dual-core, $32 \mathrm{~GB}$ RAM running Windows 7 using CONOPT (Drud 1994) in Generalized Algebraic Modeling System (GAMS) (Rosenthal 2012). GAMS offers many advantages compare to other computer optimization systems (Rosenthal 2012). In this research, GAMS software is implemented mainly because it has advance features to handle large-scale models. GAMS includes a number of solvers to solve a NLP problem, CONOPT is one of these solvers. CONOPT is designed for large and sparse models, and also it is suitable for models with highly nonlinear constraints. CONOPT may not find a global solution for non-convex models. 
However, the solvers designed for finding a global solution can not usually solve large and complex models (Drud 1994).

\section{Results for model I}

There are 19 efficient solutions out of 20 runs as shown in Fig. 4a. According to Eq. (36), when the value for $\tau(\cdot)$ increases, the right hand side of this constraint decreases. By decreasing the right hand side, feasible region of the problem increases, and the objective value improves. As it is clear from Fig. 4a, by increasing the $\tau(\cdot)$ from left to right, reliability index improves. Both objectives have maximum values in NADIR point and in UTOPIA point both objectives have their minimum values as shown in Fig. 4. It is possible to draw more accurate efficient frontiers by adjusting a greater grid point number instead of 20 , but CPU time increases. So, implementing $\varepsilon$-constraint method is efficient by defining a small grid point number; however, we have to approximate efficient frontiers with these limited points.

The result of running the model for 5 points on the Pareto set, first, last and three intermediate solutions are shown in Table 2 . In solution 19, utility has the minimum possible value and reliability index has its maximum value while the utility has its maximum value and the reliability has the minimum possible value in solution 1 . The decision maker should select one of the optimal solutions in the efficient frontier based on his/her strategy.

As it is obvious from Table 2 from solution 19 to 1 , utility value increases and travel cost decreases because the fraction of flow to capacity decreases and travel time decreases according to Eq. (13). In addition, because node 1 has less congested than node 2 as shown in Table 1, according to Eq. (8) most of the household development is allocated to node 1 .

(a)

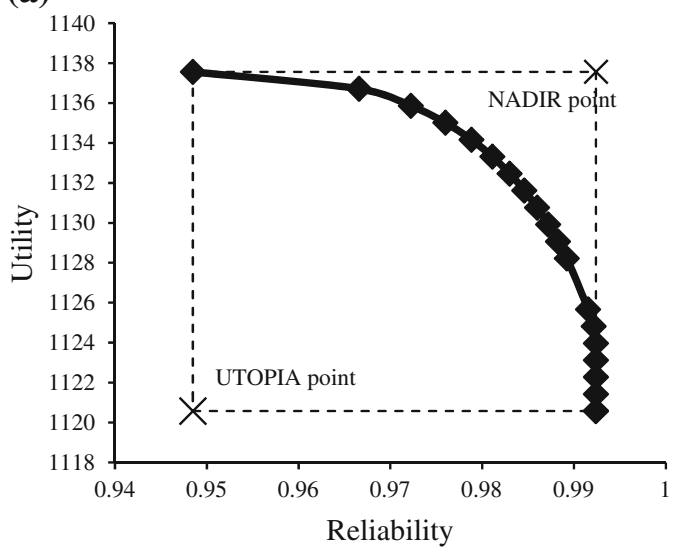

The amount of $\mathrm{CO}$ emission is calculated for each efficient solution. The relation between $\mathrm{CO}$ emission and utility is plotted in Fig. A.1 of supplementary material. By increasing utility because travel time decreases $\mathrm{CO}$ emission reduces. $\mathrm{CO}$ emission does not change significantly by increasing utility after a threshold and it stabilizes to an asymptotic value.

\section{Result for model II}

The Pareto optimal solutions of model II are shown in Fig. 4b. By increasing the emission, utility value increases. In addition, the result of the model for 4 solutions, first, last and two intermediate solutions are summarized in Table 3. The result shows that the behavior of residents for selecting residential location is almost the same in model II and model I. The difference between the results of two models is flow distribution in the network. Compared with model I, more flow is allocated to route 1, to satisfy demand between nodes 1 and 3 in model II. It is because of in this model, we also consider the length of the links. In addition, utility improves in this model. By understanding the optimum network and also current situation, network planner can define policies to attract people to use some links and routes more than others to reduce $\mathrm{CO}$ emission.

\section{Sensitivity analysis}

In any design and quantitative assessment study, it is necessary to understand the sensitivity of optimal solutions with respect to important parameters of the problem. In this section, by considering the data of the illustrative example, we change the value of the budget for network expansion and residential developments and the existing population in the origin zones to analyze the behavior of the model I and model II.

(b)

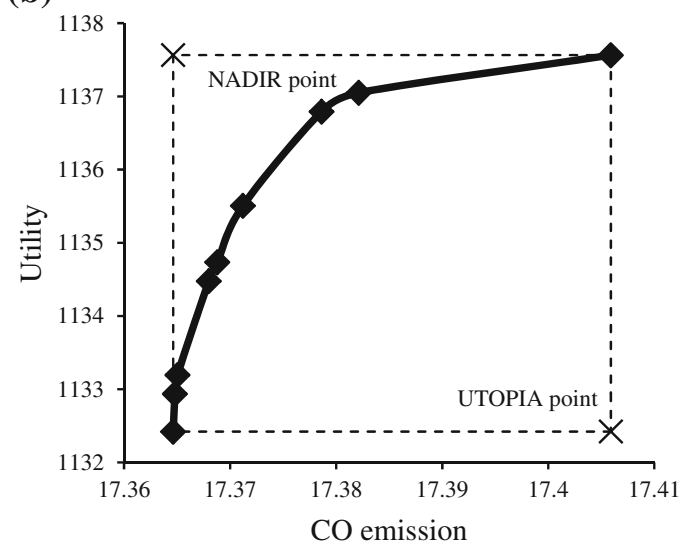

Fig. 4 Efficient frontier of the optimal solutions for $\mathbf{a}$ model I and $\mathbf{b}$ model II 
Table 2 Solutions of the illustrative example model I

\begin{tabular}{|c|c|c|c|c|c|}
\hline & 1 & 6 & 12 & 15 & 19 \\
\hline Emission index & 17.406 & 17.43 & 17.47 & 17.53 & 17.550 \\
\hline Reliability index & 0.9484843 & 0.981104 & 0.989215 & 0.99239362 & 0.99239362 \\
\hline Utility value & $1,137.565$ & $1,133.316$ & $1,128.219$ & $1,123.971$ & $1,120.572$ \\
\hline Total travel cost & 843.985 & 848.234 & 853.331 & 857.579 & 860.978 \\
\hline Total budget used & 450.000 & 450.000 & 450.000 & 450.000 & 387.069 \\
\hline $\begin{array}{l}\text { Budget used for } \\
\text { network enhancement }\end{array}$ & 200.000 & 200.000 & 200.000 & 200.000 & 137.069 \\
\hline $\begin{array}{l}\text { Budget used for land } \\
\text { development }\end{array}$ & 250.000 & 250.000 & 250.000 & 250.000 & 250.000 \\
\hline \multicolumn{6}{|l|}{ Capacity expansion } \\
\hline 1 & 15.600 & 15.600 & 15.600 & 15.600 & 15.600 \\
\hline 2 & 4.600 & 4.600 & 4.600 & 4.600 & 4.600 \\
\hline 3 & 4.600 & 4.600 & 4.600 & 4.600 & 4.600 \\
\hline 4 & 8.600 & 8.600 & 8.600 & 8.600 & 8.600 \\
\hline 5 & 15.267 & 15.007 & 14.593 & 14.341 & 0 \\
\hline 6 & 0.022 & 2.805 & 4.484 & 5.235 & 4.827 \\
\hline 7 & 8.600 & 8.600 & 8.600 & 8.600 & 8.600 \\
\hline \multicolumn{6}{|c|}{ Residential development for high income group } \\
\hline 1 & 6.000 & 1.000 & 1.000 & 1.000 & 1.000 \\
\hline 2 & 0 & 5.000 & 5.000 & 5.000 & 5.000 \\
\hline \multicolumn{6}{|c|}{ Residential development for low income group } \\
\hline 1 & 9.000 & 14.000 & 14.000 & 14.000 & 14.000 \\
\hline 2 & 5.000 & 0 & 0 & 0 & 0 \\
\hline \multicolumn{6}{|l|}{ Link flow } \\
\hline 1 & 57.411 & 45.062 & 40.733 & 38.435 & 38.435 \\
\hline 2 & 7.589 & 19.938 & 24.267 & 26.565 & 26.565 \\
\hline 3 & 21.724 & 22.025 & 22.169 & 23.685 & 24.796 \\
\hline 4 & 43.276 & 42.975 & 42.831 & 41.315 & 40.204 \\
\hline 5 & 50.865 & 62.913 & 67.098 & 67.880 & 66.769 \\
\hline 6 & 2.589 & 14.938 & 19.267 & 21.565 & 21.565 \\
\hline 7 & 48.276 & 47.975 & 47.831 & 46.315 & 45.204 \\
\hline \multicolumn{6}{|l|}{ O-D mean demand } \\
\hline Zone 1-Zone 3 & 57.411 & 58.562 & 58.562 & 60.000 & 58.562 \\
\hline Zone 1-Zone 4 & 7.589 & 6.438 & 6.438 & 5.000 & 6.438 \\
\hline Zone 2-Zone 3 & 2.589 & 1.438 & 1.438 & 0 & 1.438 \\
\hline Zone 2-Zone 4 & 62.411 & 63.562 & 63.562 & 65.000 & 63.562 \\
\hline \multicolumn{6}{|l|}{ Optimal route choice } \\
\hline Zone 1 -Zone 3 & $100 \%$ from route 1 & $\begin{array}{l}76.9 \% \text { from route } 1 \\
23.1 \% \text { from route } 2\end{array}$ & $\begin{array}{l}69.6 \% \text { from route } 1 \\
30.4 \% \text { from route } 2\end{array}$ & $\begin{array}{l}64.1 \% \text { from route } 1 \\
35.9 \% \text { from route } 2\end{array}$ & $\begin{array}{l}65.6 \% \text { from route } 1 \\
34.4 \% \text { from route } 2\end{array}$ \\
\hline Zone 1-Zone 4 & $100 \%$ from route 1 & $100 \%$ from route 1 & $100 \%$ from route 1 & $100 \%$ from route 1 & $100 \%$ from route 1 \\
\hline Zone 2 -Zone 3 & $100 \%$ from route 1 & $100 \%$ from route 1 & $100 \%$ from route 1 & $100 \%$ from route 1 & $100 \%$ from route 1 \\
\hline Zone 2-Zone 4 & $\begin{array}{l}65.2 \% \text { from route } 1 \\
34.8 \% \text { from route } 2\end{array}$ & $\begin{array}{l}65.3 \% \text { from route } 1 \\
34.7 \% \text { from route } 2\end{array}$ & $\begin{array}{l}65.1 \% \text { from route } 1 \\
34.9 \% \text { from route } 2\end{array}$ & $\begin{array}{l}63.6 \% \text { from route } 1 \\
36.4 \% \text { from route } 2\end{array}$ & $\begin{array}{l}61 \% \text { from route } 1 \\
39 \% \text { from route } 2\end{array}$ \\
\hline
\end{tabular}

We set "counter" [Eq. (36)] equal to 20 in our algorithm, so we have a number of efficient solutions for each scenario. In order to compare the results, we summarize the results for the first and last runs of each scenario that show the worst and the best value for each objective. We change the value of the allocated budget between 300 and 500. By increasing the budget, the value of reliability index and utility increase and $\mathrm{CO}$ emission reduces, as it is shown in
Fig. 5a, b. By increasing the budget, we can expand the capacities of link more, so congestion decreases in the links and reliability index increases. Also by increasing the capacity of the links, according to Eq. (13) the fraction of flow to link capacities decreases and travel time decreases, utility index increases and $\mathrm{CO}$ emission reduces. As it is shown in Fig. 5a, by more augmenting the link capacities, we can improve the reliability and utility of the network. 
Table 3 Solutions of the illustrative example for model II

\begin{tabular}{|c|c|c|c|c|}
\hline & 1 & 6 & 15 & 20 \\
\hline Emission index & 17.406 & 17.371 & 17.368 & 17.365 \\
\hline Reliability index & 0.948 & 0.960 & 0.960 & 0.965 \\
\hline Utility value & $1,137.565$ & $1,135.507$ & $1,134.479$ & $1,132.421$ \\
\hline Total travel cost & 843.985 & 846.043 & 847.071 & 849.129 \\
\hline Total budget used & 450.000 & 444.027 & 404.422 & 402.268 \\
\hline $\begin{array}{l}\text { Budget used for network } \\
\text { enhancement }\end{array}$ & 200.000 & 194.027 & 154.422 & 152.268 \\
\hline $\begin{array}{l}\text { Budget used for land } \\
\text { development }\end{array}$ & 250.000 & 250.000 & 250.000 & 250.000 \\
\hline \multicolumn{5}{|l|}{ Capacity expansion } \\
\hline 1 & 15.600 & 15.600 & 15.600 & 15.600 \\
\hline 2 & 4.600 & 4.600 & 4.600 & 4.600 \\
\hline 3 & 4.600 & 4.600 & 4.600 & 4.600 \\
\hline 4 & 8.600 & 8.600 & 8.600 & 8.600 \\
\hline 5 & 15.267 & 11.798 & 2.679 & 0 \\
\hline 6 & 0.022 & 8.600 & 8.600 & 8.600 \\
\hline 7 & 8.600 & 8.600 & 8.600 & 8.600 \\
\hline \multicolumn{5}{|c|}{ Residential development for high income group } \\
\hline 1 & 6.000 & 1.542 & 1.000 & 1.000 \\
\hline 2 & 0 & 4.458 & 5.000 & 5.000 \\
\hline \multicolumn{5}{|c|}{ Residential development for low income group } \\
\hline 1 & 9.000 & 13.458 & 14.000 & 14.000 \\
\hline 2 & 5.000 & 0.542 & 0 & 0 \\
\hline \multicolumn{5}{|l|}{ Link flow } \\
\hline 1 & 57.411 & 53.413 & 53.400 & 51.688 \\
\hline 2 & 7.589 & 11.587 & 11.600 & 13.312 \\
\hline 3 & 21.724 & 18.400 & 18.368 & 17.405 \\
\hline 4 & 43.276 & 46.600 & 46.632 & 47.595 \\
\hline 5 & 50.865 & 58.187 & 58.232 & 60.907 \\
\hline 6 & 2.589 & 6.587 & 6.600 & 8.312 \\
\hline 7 & 48.276 & 51.600 & 51.632 & 52.595 \\
\hline \multicolumn{5}{|l|}{ O-D mean demand } \\
\hline Zone 1-Zone 3 & 57.411 & 59.997 & 58.599 & 58.562 \\
\hline Zone 1-Zone 4 & 7.589 & 5.003 & 6.401 & 6.438 \\
\hline Zone 2-Zone 3 & 2.589 & 0.003 & 1.401 & 1.438 \\
\hline Zone 2-Zone 4 & 62.411 & 64.997 & 63.599 & 63.562 \\
\hline \multicolumn{5}{|l|}{ Optimal route choice } \\
\hline Zone 1-Zone 3 & $100 \%$ From route 1 & $\begin{array}{l}89 \% \text { from route } 111 \% \\
\text { from route } 2\end{array}$ & $\begin{array}{l}91.1 \% \text { from route } 18.9 \% \\
\text { from Route } 2\end{array}$ & $\begin{array}{l}88.3 \% \text { from route } 1 \\
11.7 \% \text { from route } 2\end{array}$ \\
\hline Zone 1-Zone 4 & $100 \%$ from route 1 & $100 \%$ from route 1 & $100 \%$ from route 1 & $100 \%$ from route 1 \\
\hline Zone 2-Zone 3 & $100 \%$ from route 1 & $100 \%$ from route 1 & $100 \%$ from route 1 & $100 \%$ from route 1 \\
\hline Zone 2-Zone 4 & $\begin{array}{l}65.2 \% \text { from route } 1 \\
34.8 \% \text { from route } 2\end{array}$ & $\begin{array}{l}71.7 \% \text { from route } 1 \\
28.3 \% \text { from route } 2\end{array}$ & $\begin{array}{l}71.1 \% \text { from route } 1 \\
28.9 \% \text { from route } 2\end{array}$ & $\begin{array}{l}72.6 \% \text { from route } 1 \\
27.4 \% \text { from route } 2\end{array}$ \\
\hline
\end{tabular}

Also, $\mathrm{CO}$ emission reduces as it is shown in Fig. 5b. The detail results for models I and II are summarized in Tables A. 1 and A. 2 of supplementary material, respectively.

We change the existing population in origin nodes from 60 to 50 in node 1 and node 2, respectively, to (50-60),
(55-55) and (45-65). In each scenario, most amount of the population growth is allocated to the origin nodes with less existing population because of less crowded zones are more attractive according to Eq. (7). The detail results are provided in Tables A.3 and A.4 of supplementary material. 
(a)

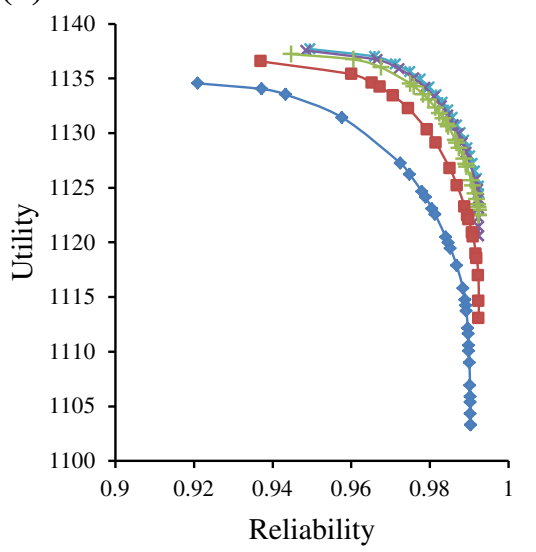

(c)

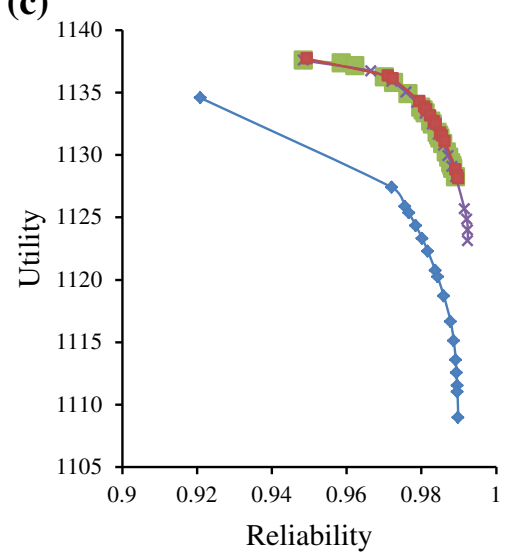

(b)

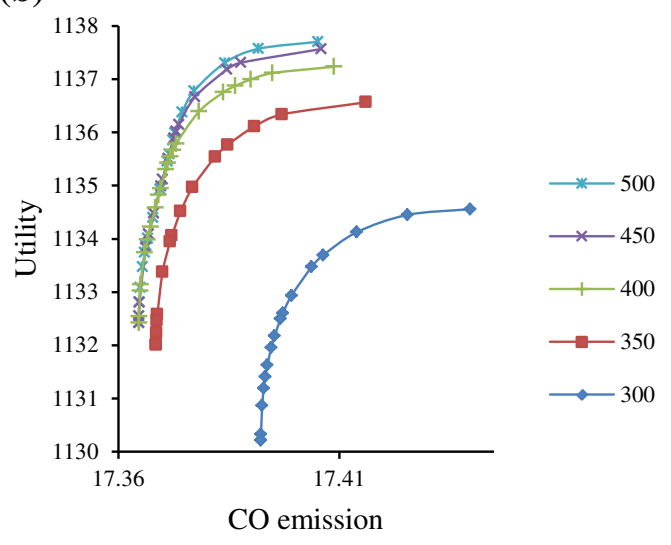

(d)

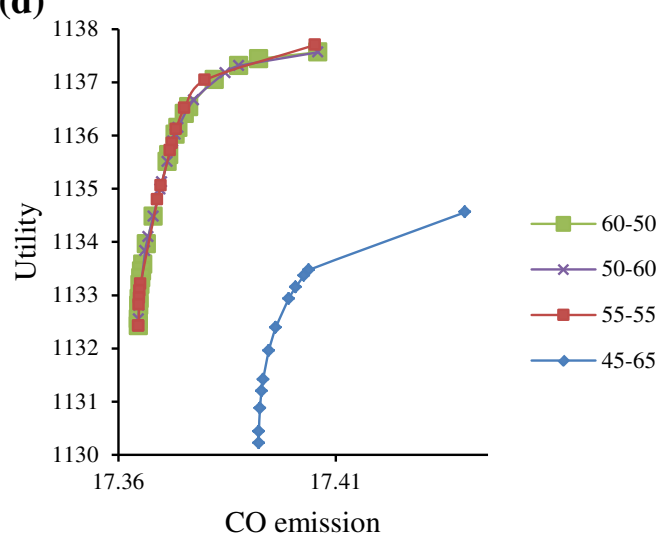

Fig. 5 Efficient frontiers by changing the budget for a model I and $\mathbf{b}$ II and changing zonal existing population for $\mathbf{c}$ model I and $\mathbf{d}$ II

In addition, efficient frontiers of optimal solutions are shown in Fig. 5c, d. We can conclude from Fig. 5c, d that by distributing the population more symmetric in the origin and destination nodes, the reliability and utility in the network improve and $\mathrm{CO}$ emission reduces.
Results for a large set of problems

To evaluate the performance of our integrated model, we generate different layouts for the city network using JAVA programming language and by implementing the generated

Table 4 Complexity of the problem

\begin{tabular}{|c|c|c|c|c|c|c|c|c|c|}
\hline \multirow[t]{2}{*}{ No } & \multirow[t]{2}{*}{ Scenario name } & \multirow[t]{2}{*}{ \# Of nodes } & \multirow[t]{2}{*}{ \# Of links } & \multirow[t]{2}{*}{ \# Of variables } & \multirow[t]{2}{*}{ \# Of equations } & \multicolumn{2}{|c|}{ \# Of efficient solutions } & \multicolumn{2}{|c|}{ CPU time (s) } \\
\hline & & & & & & Model I & Model II & Model I & Model II \\
\hline 1 & $(2,2,3,1)$ & 5 & 4 & 195 & 195 & 10 & 10 & 0.078 & 1.25 \\
\hline 2 & $(2,2,3,2)$ & 6 & 8 & 421 & 482 & 10 & 10 & 23.026 & 17.862 \\
\hline 3 & $(2,2,3,3)$ & 7 & 12 & 695 & 827 & 10 & 10 & 27.937 & 22.557 \\
\hline 4 & $(2,2,3,4)$ & 8 & 16 & 1,017 & 1,253 & 10 & 8 & 246.433 & 30.046 \\
\hline 5 & $(3,3,3,3)$ & 9 & 18 & 1,233 & 1,527 & 7 & 8 & 33.18 & 321.987 \\
\hline 6 & $(3,3,3,4)$ & 10 & 24 & 1,851 & 2,381 & 10 & 10 & 163.834 & 79.766 \\
\hline 7 & $(4,4,3,3)$ & 11 & 24 & 1,899 & 2,420 & 10 & 9 & 235.968 & 391.654 \\
\hline 8 & $(3,3,4,3)$ & 12 & 27 & 2,322 & 2,958 & 10 & 7 & 519.67 & 452.387 \\
\hline 9 & $(5,5,3,3)$ & 13 & 30 & 2,693 & 3,507 & 10 & 9 & 316.197 & 420.111 \\
\hline 10 & $(4,4,4,3)$ & 14 & 33 & 3,276 & 4,204 & 10 & 9 & $1,684.622$ & $1,665.605$ \\
\hline
\end{tabular}


(a) 2231

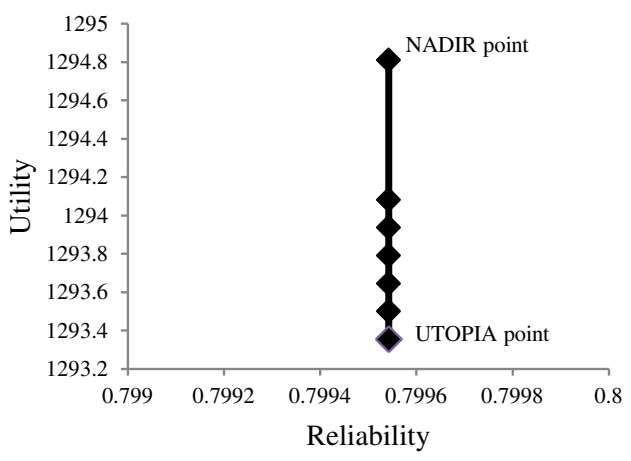

(c)

2233

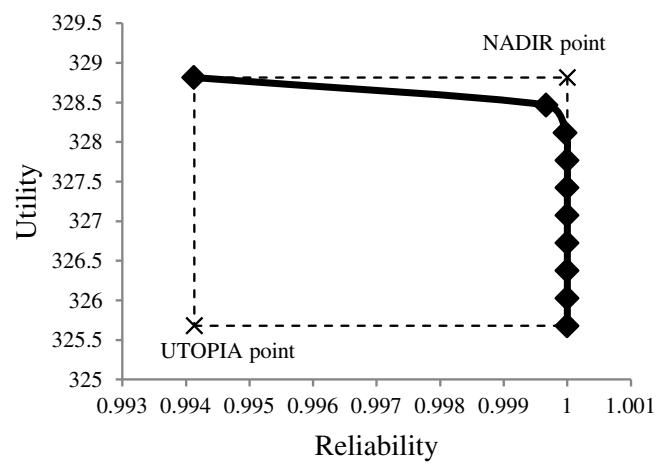

(e)

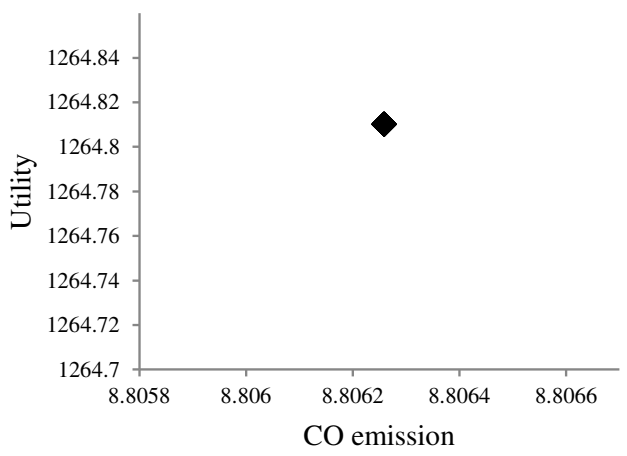

(g)

2233

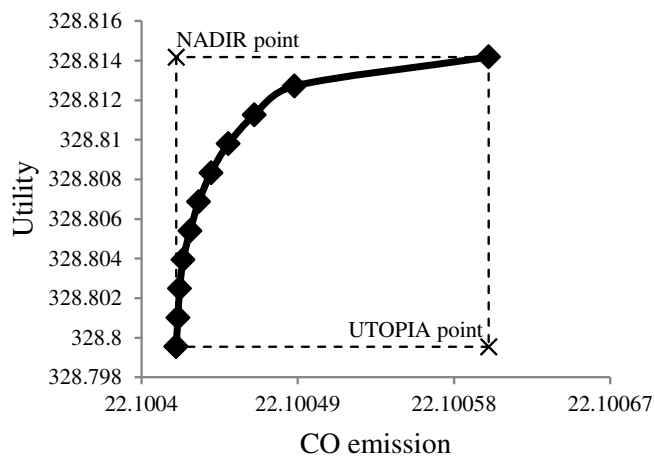

(b)
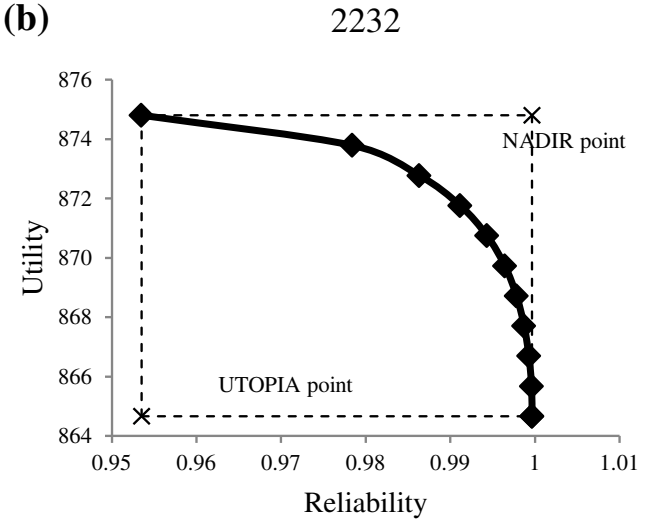

(d)

2234

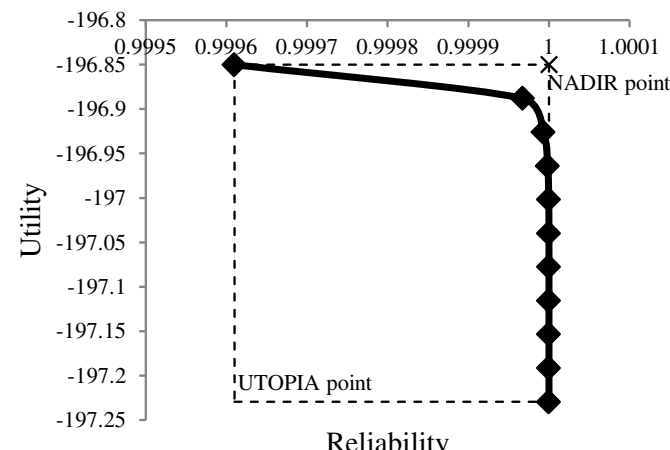

Reliability

(f)

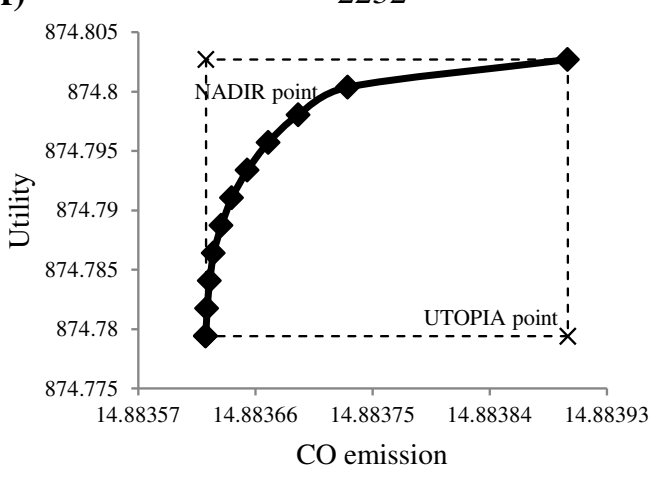

(h)

2234

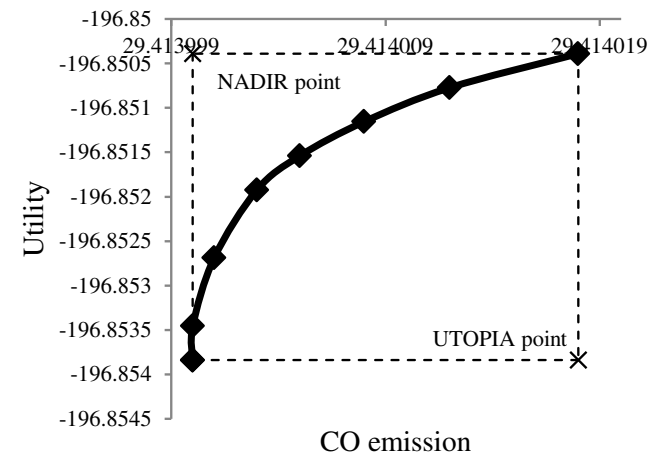

Fig. 6 The efficient frontiers of problem a "2,2,3,1", b "2,2,3,2", c "2,2,3,3" and $\mathbf{d}$ " $2,2,3,4$ " for model I and the efficient frontiers of problem e " $2,2,3,1$ ”, f " $2,2,3,2$ ”, $\mathbf{g}$ “ $2,2,3,3$ ” and $\mathbf{h}$ " $2,2,3,4$ ” for model II 
layout we develop models I and II and solve them in GAMS environment. We change 4 parameters, $p, q, s$ and $n$, which show, respectively, the number of origin nodes, the number of destination nodes, the number of echelons and the number of nodes in the intermediate echelons to generate different feasible layouts. After determining the values for $p, q, s$ and $n$, links will connect all nodes in each echelon to all nodes in the previous and subsequent echelons. The number of routes that connect each origin node to each destination node will be counted and it will consider in the models. By changing the values of $p$ and $q$ between 2 and 5, the value of s between 3 and 4 and the value of $\mathrm{n}$ between 1 and 5 , we create 10 scenarios of which are labeled by vector $(p, q, s$ and $n)$. These ten scenarios are selected because they have different number of nodes and links, and we can survey the relation between number of nodes and links of a network with CPU time.

For these examples, we consider 60 existing population for each node in origin and destination nodes and we consider 20 population developments. The data related to links is considered the average values of each parameter in Table 1, and the data related to income group is considered the same as the data in Table 1 . The networks structures of these ten problems are given in the supplementary material.

The results presented in Tables 4 show the problem complexity, model statistics and the CPU time required to obtain optimal solutions to each problem. The set of 10 scenarios are successfully optimized in reasonable CPU times for all values considered.

The first four problems listed in Table 4 have the same number of origin and destination nodes, but from first to fourth one, the numbers of links in the network increase. As shown in the efficient frontiers of these four problems for model I in Fig. 6a, b, c and d, by increasing the number of links, the minimum and maximum values of the reliability index increases and the maximum value approaches to 1 . Because by increasing the number of links in the network and having the same population, flow in links decreases and congestion decreases and reliability increases. But the utility value decreases because travel time increases and travel cost increases. We have the same condition for problems $(3,3,3,3),(3,3,3,4)$ and $(3,3,4,3)$, also for problems $(4,4,3,3)$ and $(4,4,4,3)$ as shown in Fig. A. 6 and Fig. A. 8 of the supplementary material. In addition, the efficient frontiers of optimal solutions of the first four problems are plotted for model II in Fig. 6e, f, $g$ and $\mathrm{h}$. As it is shown in Fig. 6e, $\mathrm{f}, \mathrm{g}$ and $\mathrm{h}$ by increasing the number of links the minimum and maximum values for utility index decrease and minimum and maximum values for $\mathrm{CO}$ emission increase, because travel time increases in the larger networks. We conclude same results for problems $(3,3,3,3),(3,3,3,4)$ and $(3,3,4,3)$, also for problems
$(4,4,3,3)$ and $(4,4,4,3)$ as shown in Fig. A. 7 and Fig. A. 9 of the supplementary material. So, the best topology can be a structure that considers trade-off between two situations, very low land use intensity and degree of concentration structure, and very high-density land use structure. By considering the result of sensitivity analysis part, we can conclude that expanding the capacity of the existing links is a better policy than constructing new links for expanding a city network. Because by augmenting the capacity of the links, we can improve the reliability, utility and $\mathrm{CO}$ emission in urban areas.

\section{Conclusion}

In this paper, we present two bi-objective optimization models for land use and transportation problem. Objective functions of the first model are utility value and reliability index, and objective functions of second model are utility value and amount of $\mathrm{CO}$ emission. Relation among land use structure, transportation network and amount of $\mathrm{CO}$ emission is analyzed.

By defining reliability probability, we minimize congestion. We formulate a closed form expression to calculate the Cholesky factorization matrix that is implemented as a set of constraints in the optimization model, to estimate the reliability index by multivariate normal distribution. Utility value captures travel time and attractiveness of each zone as a cost function. We use BPR link impedance function to estimate average travel time. In addition, we consider zonal attractiveness as a function of intensity or congestion of each zone. And, $\mathrm{CO}$ emission is calculated by an equation which is function of travel time and speed in each link.

We used $\varepsilon$-constraint method as a solution algorithm, and we analyzed model behavior through several experiments. We tested our approach on ten different problems with different sizes as summarized in Table 4 . We found that CPU time does not suffer from the size of the problems. By analyzing the model behavior in "Sensitivity analysis" and "Results for a large set of problems" section, we found that expanding the capacity of existing links instead of constructing the new links can be a better policy. By augmenting the link capacities, both reliability and utility improve, while by constructing the new links just reliability improve. In addition, amount of $\mathrm{CO}$ emission reduces by augmenting the link capacities. Besides, distributing the population more symmetrically in the origin and destination zones can help to improve the reliability and the utility of the network and reducing $\mathrm{CO}$ emission. Considering $\mathrm{CO}$ emission as objective function instead of reliability index effects on the distribution of flow in the network and improves the utility value. 
Acknowledgments Financial Support for this work from the European Commission LOG4GREEN Project Grant \#287091 under FP7 program is gratefully acknowledged.

\section{References}

Abbaspour M, Soltaninejad A (2004) Design of an environmental assessment model on the effect of vehicle emission in greater Tehran on air pollution with economic sensitivity. Int J Environ Sci Tech 1(1):27-38

Alam JBM, Alam MJB, Rahman MH, Khan SK, Munna GM (2006) Unplanned urbanization: assessment through calculation of environmental degradation index. Int $\mathrm{J}$ Environ Sci Technol $3(2): 119-130$

Anas A (1987) Modeling in urban and regional economics. Harwood Academic Publishers, GmbH, Chur

Anderstig C, Mattsson L (1998) Modeling land-use and transport interaction: evaluations and policy analysis. In: Lundqvist L, Mattsson LG, Kim TJ (eds) Network infrastructure and the urban environment: recent advances in land-use/transportation modeling. Springer, Berlin, pp 308-328

Ban JX, Liu HX, Ferris MC, Ran B (2006) A general MPCC model and its solution algorithm for continuous network design problem. Math Comput Model 43:493-505

Bravo M, Briceno L, Cominetti R, Cortes CE, Martinez FJ (2010) An integrated behavioral model of the land-use and transport systems with network congestion and location externalities. Transp Res Part B 44(4):584-596

Chang J, Mackett R (2006) A bi-level model of the relationship between transport and residential location. Transp Res Part B 40:123-146

De la Barra T, Pérez B, Vera N (1984) TRANUS-J: putting large models into small. Comput Environ Plan B Plan Design 11:87-101

Deb K (2001) Multi-objective optimization using evolutionary algorithms. Wiley, Chichester

Dowling R, Ireson R, Skabardonis A, Gillen D, Stopher P (2005) Predicting air quality effects of traffic-flow improvements: final report and user's guide. Technical Report No. 535. National Cooperative Highway Research Program, Transportation Research Board, National Research Council, Washington, DC

Drud AS (1994) CONOPT: a large-scale GRG code. ORSA J Comput 6(2):207-216

Echenique MH, Crowther D, Lindsay W (1969) A spatial model for urban stock and activity. Reg Stud 3:281-312

Environmental Protection Agency (2000) Projecting land-use change: a summary of models for assessing the effects of community growth and change on land-use patterns. Technical Report EPA600-R-00-098. US Environmental Protection Agency, Office of Research and Development, Cincinnati, OH, p 260

Environmental Protection Agency (2010) Carbon monoxide-NAAQS implementation. http://www.epa.gov/ttn/naaqs/co/index.html. Accessed Nov 2010

Ferguson EM, Duthie J, Waller ST (2010) Network methods for project selection based on optimizing environmental impact. Research report SWUTC/10/161026-1. University of Texas at Austin, Austin

FHWA (2006) Transportation air quality facts and figures. http:// www.fhwa.dot.gov/environment/air_quality/publications/fact_ book/index.cfm. Accessed Nov 2010

Garret M, Wachs M (eds) (1996) Transportation planning on trial: the clean air act and travel forecasting. Sage, Thousand Oaks, CA

Genz A (1992) Numerical computation of multivariate norm probabilities. J Comput Graph Stat 1:141-149
Ho HW, Wong SC (2007) Housing allocation problem in a continuum transportation system. Transportmetrica 3:21-39

Huang K, Zhang J, He M, Liao W (2010) An optimal model and solution algorithm of urban traffic network considering exhaust emission control. In: Proceedings of the 2010 international conference of logistics engineering and management, pp 528-534

Hui X, Kefei Y (2009) A bi-level programming model of urban land use and network design problem. In: 2nd International conference on power electronics and intelligent transportation system

Ibeas A, Cordera R, dell Olio L, Coppola P (2013) Modelling the spatial interactions between workplace and residential location. Transp Res Part A 49:110-122

Kanaroglou P, Scott D (2002) Integrated urban transportation and land-use models for policy analysis. In: Xdijst V, Schenkel W, Thomas I (eds) Governing cities on the move: functional and management perspectives on transformations of European urban infrastructures. Ashgate, Aldershot, pp 43-73

Kim BJ, Kim WK, Song BH (2008) Sequencing and scheduling highway network expansion using a discrete network design model. Ann Reg Sci 42(3):621-642

Kitamura R, Susilo YO (2005) Is travel demand is insatiable? A study of changes in structural relationships underlying travel. Transportmetrica 1:23-45

Li ZC, Lam WHK, Wong SC, Sumalee A (2012) Environmentally sustainable toll design for congested road networks with uncertain demand. Int J Sust Transp 6(3):127-155

Liao CH, Chang CL, Su CY, Chiueh PT (2013) Correlation between land-use change and greenhouse gas emissions in urban areas. Int J Environ Sci Technol 10(6):1275-1286

Lin JJ, Feng CM (2003) A bi-level programming model for the land use-network design problem. Ann Reg Sci 37:93-105

Lo HK, Szeto WY (2009) Time-dependent transport network design under cost-recovery. Transp Res Part B 43(1):142-158

Lowry IS (1964) A model of metropolis. RM-4035-RC. The Rand Corporation, Santa Monica

Ma X, Lo HK (2012) Modeling transport management and land use over time. Transp Res Part B 46:687-709

Mackett RL (1983) The leeds integrated land-use transport model (LILT). Supplementary report SR 805 transport and road research laboratory, Crowthorne, Berkshire

Martinez FJ (1992) The bid choice land use model: an integrated economic framework. Environ Plan A 24:871-885

Martinez FJ (1996) MUSSA: a land use model for Santiago City. Transp Res Rec 1552:126-134

Miandoabchi E, Zanjirani Farahani R, Dullaert W, Szeto WY (2012a) Hybrid evolutionary metaheuristics for concurrent multi-objective design of urban road and public transit networks. Netw Spat Econ 12(3):441-480

Miandoabchi E, Zanjirani Farahani R, Szeto WY (2012b) Biobjective bimodal urban road network design using hybrid metaheuristics. CEJOR 20(4):583-621

Miller E, Kriger D, Hunt J (1999) Integrated urban models for simulation of transit and land use policies. Final report, Project H-12, TCRP Web Document 9. Transit Cooperative Highway Research Project, National Academy of Sciences, Washington, DC

Newman PWG, Kenworthy JR (1989) Cities and automobile dependence: a sourcebook. Gower, Brookfield, Vt

$\mathrm{Ng} \mathrm{M}$, Lo HK (2013) Regional air quality conformity in transportation networks with stochastic dependencies: a theoretical copula-based model. J Netw Spat Econ 13:373-397

Paulley N, Webster F (1991) Overview of an international study to compare models and evaluate land use and transport policies. Transp Rev 11:197-222 
Putman SH (1983) Integrated urban models: policy analysis of transportation and land use. Pion, London

Rodrigue JP, Comtois C, Slack B (2006) The geography of transport systems. Routledge, London

Rosenthal RE (2012) GAMS: a user's guide. GAMS Development Group, Washington, DC

Sharma S, Mathew TV (2011) Multi-objective network design for emission and travel time tradeoff for sustainable large urban transportation network. Environ Plan B 38(3):520-538

Sheffi Y (1985) Urban transportation networks: equilibrium analysis with mathematical programming methods. Prentice-Hall Inc, Englewood Cliffs, NJ

Simmonds DC, Still BG (1998) DELTA/START: adding land use analysis to integrated transport models. In: The 8th world conference on transport research, Antwerpen

Southworth F (1995) A technical review of urban land use: transportation models as tools for evaluating vehicle reduction strategies. U.S. Department of Energy, Washington, DC

Szeto WY, Jiang Y (2013) A sustainable road network design problem with land use transportation interaction over time. In: Proceeding of 91th annual meeting of the transportation research board, Washington, DC

Szeto WY, Jaber XQ, O’Mahony M (2010) Time-dependent discrete network design frameworks considering land use. Comput Aided Civ Infrastruct Eng 25(6):411-426

Timmermans H (2003) The saga of integrated land use-transport modeling: how many more dreams before we wake up? In: 10th International conference on travel behavior research, Lucerne, International Association for Travel behavior Research, 10-15 August
Waddell P, Ulfarsson G, Franklin J, Lobb J (2007) Incorporating land use in metropolitan transportation planning. Transp Res A Policy Pract 41:382-410

Wegener M (1995) Current and future land use models. In: Proceedings of land use modeling conference, Arlington

Wegener M (1998b) The IRPUD model: overview

Wegener M (2004) Overview of land use transport models. In: Hensher DA, Button KJ, Haynes KE, Stopher PR (eds) Handbook of transport geography and spatial systems. Pergamon, Amsterdam, pp 127-146

Wegener M, Furst F (2004) Land-use transport interaction: state of the art. Institut fur Raumplanung, Dortmund

Yang H, Xu W, He B, Meng Q (2010) Road pricing for congestion control with unknown demand and cost functions. Transp Res C 18(2):157-175

Yim KKW, Wong SC, Chen A, Wong CK, Lam WHK (2011) A reliability-based land use and transportation optimization model. Transp Res Part C 19(2):351-362

Yin Y, Lawphongpanich S (2006) Internalizing emission externality on road networks. Transp Res Part D 11(4):292-301

Yin Y, Lu H (1999) Traffic equilibrium problems with environmental concerns. J East Asia Soc Transp Stud 3(6):195-206

Zhong RX, Sumalee A, Maruyama T (2012) Dynamic marginal cost, access control, and pollution charge: a comparison of bottleneck and whole link models. J Adv Transp 46(3):191-221

Zhou S, Yan X, Wu C (2008) Optimization model for traffic signal control with environmental objectives. In: Proceedings of the 4th International conference on natural computation (pp 530-534), Jinan, October 18-20 